\title{
REFERENCIAL SEMANTICS AND THE MEANING OF NATURAL KIND TERMS
}

\author{
Ralph Henk Vaags \\ University of Agder
}

\begin{abstract}
In this article I have taken certain ideas from Montague-semantics as my starting point, and distinguished clearly semantics from epistemology. The meaning of a sentence is said to be its truth conditions, which are assumed to be established by two components: syntactical structure and the referents of structureless terms. On this theoretical background, I try to give an account for the meaning of natural kind terms. My thesis is that the meaning of natural kind terms is its reference, i.e. the natural kind, which the term refers to.Resumo
\end{abstract} Keywords: Reference, meaning, natural kind terms, semantics.

Resumo: Neste artigo, tomei certas idéias da semântica de Montague como meu ponto de partida e distingui claramente semântica de epistemologia. O significado de uma sentença é considerado como suas condições de verdade as quais são assumidas como sendo estabelecidas por dois componentes: a estrutura sintática e os referentes de termos sem estrutura. Nesse panorama teórico, tento apresentar uma explicação para o significado dos termos de espécies naturais. Minha tese é que o significado de um termo de espécie natural é sua referência, i. e., a espécie natural à qual o termo refere-se.

Palavras-chave: Referência, significado, termos de espécies naturais, semântica

\section{Introduction}

Among philosophers the term "natural kind" refers to a group of things, which is a natural group in contrast to artificial grouping. Then the real use of the term presupposes that there are such groups, and not only individual things grouped together more or less arbitrary by us. Whether there are such natural groups or divisions of things is under philosophical 
debate. Uses of natural kind terms raise a lot of questions. I shall not go into all of them, off course, but give attention to the problem of meaning of terms that intend to refer to natural kinds.

The question I will try to answer is the following: What is the meaning of natural kind terms and how do such terms refer? It is common among philosophers to make a distinction between meaning and reference, and often with a reference to Frege. I shall, however, maintain a referential theory of meaning for natural kind terms, and, therefore, a theory of reference is included in my theory of meaning. It is, however, my strategy to answer the problem of reference for natural kind terms on the basis of a theory of reference for proper names. In my opinion, proper names give the paradigmatic example of reference in general.

When I connect meaning and reference in such a strong way, it's not my intention to identify meaning and reference in the sense that a theory of reference is a theory of meaning. A theory of reference is a theory that explains how an expression in language relates to what the expression is about, for example how "Socrates" refers to Socrates himself or how "gold" refers to gold itself, but do not in itself explain what it is for a longer expression in language to have meaning. My point of view is that a theory of reference is included in a theory of meaning, but needs additional components for handling with sentences. In the following, I will try to describe how a full theory of meaning for a specific language L (which I will specify later) can be given, on the basis of a theory of reference for proper names. In order to do this, I will make a sharp distinction between semantic meaning and pragmatic meaning of expressions in $\mathrm{L}$.

\section{A semantic program}

In order to make a theory of meaning clear enough for an answer to the question of the meaning of natural kind terms or expression containing natural kind terms, I will start by explaining my point of view on semantics, and which components constitute meaning. After that, I will answer the question of the meaning of natural kind terms.

Natural kind terms are strong components in the language we use when we intend to talk about things in the world. In fact, it is a typical indicator for such use of language: 
(1) The tiger is running.

(2) This ring is made of gold.

(3) Everybody needs oxygen to live.

The kind of language we use when we talk about things in the world, therefore, is of special interest for us, and I will describe my view of how a semantic theory for such use of language can be developed within an empiric framework. This empirical approach can, I assume, be called 'soft empiricism', and entails giving empirical data precedence over other data when a conflict arises in relation to non-empirical data. ${ }^{1}$ Furthermore, it involves the desire to put forward semantic hypotheses that in one way or another can be confronted by empirical data. ${ }^{2}$ Within the frame of this soft empiricism I shall attempt to formulate a semantic programme.

Any semantics aims to account for meaning, and then also for that kind of language which I will give attention here, namely language used to say something about existing things. I will call this specific kind of language "L". It is my view that semantics for $\mathrm{L}$ can be created through a three-stage process:

(A) An account of meaning for every use of a sentence in L by referring to its conditions of truth.

(B) An account of how conditions of truth sentences in $\mathrm{L}$ are conditional on the structural role and the referential characteristics of the component elements.

\footnotetext{
${ }^{1}$ By data I here refer to forms of understanding that have as their basic function to account/to explain. The intuitions of competent language users will for example be able to function as data in this inquiry. Data is, therefore, everything that I at the last count refer to in my argumentation or test my assumptions against. There will be an extensive intersubjective agreement on these data. However, this must not be perceived as a form of epistemic fundamentalism.

2 Intuitively, I can distinguish between three types of data that appear relevant: Firstly, there are facts about the relationship between linguistic expressions and the world in which we live. Through for example discussions on the world factual relationships about language will become apparent. In other words, conversations about how the world is recognized the relationship of language to the world, and how language is built up. Secondly, we have data on linguistic expressions such as the following: their characteristics, and the relationships that exist between these characteristics. Thirdly, there are the factual conditions regarding the relation between linguistic expressions and the language user. Language is a mean of communicating thoughts, for the execution of speech acts etc. These conditions manifest themselves empirically, and a semantic theory should be confronted by this fact. Given the semantics I will claim, it would seem to be the case that there is only one type of ambiguity, namely syntactical ambiguity. The reason for this is that the referent is decided without ambiguity. Another possibility is to talk of 'phonetic ambiguity' e.g. when two identically sounding names refer to different people. So-called "semantic ambiguity" and "pragmatic ambiguity" are concerned with pragmatic relations and must be seen as the ascription of meaning and intension (speech acts)).
} 
(C) An account of the referential characteristics of the component elements in $\mathrm{L}$.

The first stage, (A), is in line with a well-established tradition in modern philosophy of language. It was Frege's idea that the meaning of a sentence is found in its truth conditions. ${ }^{3}$ This, however, can be understood in two different ways; either as a set of conceptualised truth conditions, i.e. how we must conceive the world if the sentence were to be true; or, more realistically as the world as it is when the sentence is true. I will take a midway position here, in as much as I see meaning as dependent on the existence of what one talks about. But what one says about this existence needs not answer to anything in reality. This is exactly when the sentence is untrue. But, if that which one intends to talk about does not exist, I will say that the sentence lacks semantic meaning. We believe what we say to have meaning, but, in fact, it is merely a psychological addition.

Task (B) consists in showing how the structural role and referential characteristics of the component elements determine the truth conditions each time something existing is talked about. Already in (A), I express my understanding of meaning as being dependent on reference. It also seems, however, that truth conditions will vary in relation to the sentence's logical form, i.e. vary relative to how the component elements interrelate structurally. To account for which role such structural conditions play for meaning, we can make use of Montague's insights, as well as further developments to be found in modern logical semantics. ${ }^{4}$ In my opinion, this

\footnotetext{
${ }^{3}$ The relationship between the truth conditions of a sentence and their meaning has been accounted for in different ways. Davidson has claimed that Tarski's theory of truth can be understood as a theory of meaning, since Tarski's theory of truth shows how the conditions of truth for a statement are conditional on the components of the statement (which also occur in other statements). To know the semantic term for truth for a language is at the same time to know what it means for a statement to be true. In short, I can put it in this way: Davidson claims that the meaning of a statement is given when the truth conditions of that statement are given (Davidson 1967). This can be seen as an attempt to identify the meaning of the sentence and the truth conditions of the statement. At least, this is how Davidson has been interpreted by amongst others Michael Devitt (Devitt 1983). Whether or not this is a correct interpretation of Davidson, it is not clear. Davidson has - to the best of my knowledge - never explicitly claimed such an identity.

${ }^{4}$ That there is an intimate relationship between meaning and structure is also expressed in Frege's socalled compositionality thesis. In the same way that the truth value of a complex statement, $\Omega$, is conditional on the truth values ascribed to the atomic statements in $\Omega$, the truth value of an atomic statement will be conditional on its component elements. Thus, the structure of complex and atomic statements will play a decisive role in the ascription of truth value. If, then, meaning and truth are cojoined (cf. earlier footnote) we can maintain, in a parallel way, that the meaning of a statement depends on the meaning of its parts. Montague, like Davidson, found inspiration in Tarki's thoughts about truth.
} 
tradition has a great deal of value to contribute - both terms and techniques - in the analysis of central aspects of meaning when one talks of things/entities or kinds of things.

A complex motivation lies behind the wish of a formal or logical semantics. Semantic theory can easily become unclear, and a clearly defined tool for semantic analysis is in itself desirable. But, the most important motivation is that logic clarifies the structure of language, and is, thus, an important component in the very aspect of meaning.

The last task, (C) involves accounting for the referential characteristics of the component elements of which the sentence is made up. In this paper, I will first and foremost be concerned with proper names and natural kind terms, even though a complete semantics must account for all the component elements in language.

(C) is in line with what is said for (A). Central to a semantics that bases its account of meaning on truth conditions, is the relationship between language and reality. The nature of reality is of course a difficult question, but require some comments when the topic is natural kind terms. When I connect meaning with ontology, as I do, the question of existence of natural kinds rises at once. I will, however, not go deep into this problem, though I will presuppose a kind of essentialism and make a distinction between nominal and real essence.

There are, however, semantic positions which disregard the relationship between language and reality. Such positions claim, for example, that the meaning of sentences can be identified by translating them into another language. This other language can be a system of semantic indicators or some version of formal logic. This is, then, achieved without considering the relationship of language to reality. Well-known representatives of such a strategy are Katz and Fodor (1963), or representatives of generative semantic: Lakoff (1972) or McCawley (1973). These approaches are strange, to my

Montague lays the theoretical basis for the development of a semantics for natural language (English) which is completely in line with the semantics we find for formal language, i.e. via the theory of models. Both Tarski and Montague focus on the truth-bearing components in language, and account for the truth conditions of statements in this way. On this basis, Montague can account for the meaning of statements. Meaning is, therefore, explained in terms of truth and Tarski's concept of satisfaction. A development of Montague's approach is to be found in e.g. Jon Barwise and Hans Kamp. Barwise makes use of transformational grammar (Noam Chomsky), as well as Montague's semantics. 'As to my use of Montague's writings, it will not lead me into the controversies and nuances that exist between these further developments. It is important for me to go further than to truth and satisfaction to account for semantic meaning. For me, semantics must also account for reference. cf. (C). 
mind, since I perceive the ability of language to say something about reality as central for communication and experience. At the very least, their approach is useless in relation to the problem that motivates this inquiry, namely the problem of meaning for talking about natural kinds.

To follow (A), (B) and (C) will result in a semantics which can also be called 'referential', since the relation of reference will constitute the place where meaning is given to the component elements. This approach to meaning is different to the approach we find in early positivistic positions, though these positions also let the relationship of language to reality play a decisive role in the accordance of meaning. The difference is that the positivist accounts for meaning from an epistemic understanding of this relationship, whilst, I see the relation as semantic and factual. This raises a question about what semantics is.

\section{The Concept of Semantics}

My view on theory of meaning is based on a radical distinction between semantics and epistemology. 'Semantics' in this inquiry has the same extension as 'the study of meaning and reference in language'. My point of departure is, therefore, in line with a traditional understanding of semantics. I perceive the objects of semantics, however, meaning and reference, as factual - or more exactly: as conditional on exclusively factual matters. There is nothing to account for regarding meaning and reference than that which is given in the real state of affairs, independent of human consciousness. This implies that what is conditioned by a person's epistemic possibilities is not perceived as within the domain of semantics. I do not mean by this to claim that actual use of language is outside this domain. The focus or concern of semantics is not the use of language as such, but meaning and reference. All the same it is the case that meaning and reference manifest themselves through the use of language. Therefore, actual use of language provides evidence that a semantic theory must be tested with. Misunderstandings and other systematic errors will make up an especially important source that semantics must be able to account for. The idea is that misunderstandings can be accounted for in that our assumptions about meaning and reference, in these cases, are incorrect. It is desirable to be able to state exactly what sort of assumptions are incorrect in the concrete instances of misunderstanding. This means that semantics shall identify the conditions for successful 
reference and expressions of meaning, which I understand to be identical to giving the necessary and sufficient conditions for meaning and reference. Full understanding is, therefore, to take over these conditions successfully. ${ }^{5}$ Since meaning is perceived through a set of truth conditions, a misunderstanding could arise when a recipient does not know which truth conditions apply for the sentence that the sender actually utters.

Misunderstandings occur when a language user does not possess knowledge of a sentence's truth conditions. At this juncture, I will, therefore, make a sharp distinction between two different communicative tasks: (i) To understand what the sender actually says (the semantic task), and (ii) to understand what the sender intends to express (the secondary/pragmatic task). The last type of task will come into full force when we suspect that the other person has not expressed him/herself correctly in relation to the assumed context for the conversation. ${ }^{6}$ However, if such a suspicion does not arise, the communication gives the participants a semantic task, i.e. each of them uses the evidence that indicates what is actually said. ${ }^{7}$

A competent language user is in possession of information about meaning and reference. The fact that we can talk about and discuss what goes on in the world through language is to my mind strong evidence that the semantic knowledge we possess and which makes it possible is largely correct/true. However, I do not accept that a semantic theory on its own can

\footnotetext{
${ }^{5}$ One can now distinguish between full and sufficient understanding. Full understanding can be said to exist when the language user can state the concrete truth conditions for the utterance. Sufficient understanding can be understood in relation to the communicative background, i.e. in relation to the possibility for the communication to flow on: Sufficient communication presumes e.g. that the participants refer to the same object when they use the logical subject of their utterances. For talk about natural kinds this implies that both refer to water with 'water'.

${ }^{6}$ My semantics cannot be said to be contextual in the sense that the meaning of a statement is conditioned by the context in which the statement is found. This must not be misunderstood. It is my view that context plays an important role for an account of language understanding, i.e. in explaining how we establish the attribution of meaning. The language user makes use of all the evidence available to give language an adequate meaning, and in this connection context provides an important source of evidence. On the other hand, the semantics I present is relative to the language user in the sense that referential expressions in the language refer by virtue of the language users choice of referential norm. It is this freedom of choice that makes it possible for referential expressions like 'you', 'I' 'now' etc. (indicators) to be referentially manifold. In connection with the use of proper names, the recipient will then typically ask to whom is the sender referring? In a communicative situation, the recipient will make use of his/her knowledge of the sender, amongst other things, to find the most adequate attribution of meaning possible. These formulations will be developed later in the inquiry.

${ }^{7}$ One could of course here have chosen another way to attempt to account for meaning, e.g. referring to rules. But this implies that rules cannot be understood as private. I will later make use of norms of reference in an attempt to account for the relation of reference for terms about natural kinds.
} 
make this knowledge explicit. We also need criteria that tell us what about this knowledge is correct and what leads us astray. This leads my semantic project beyond a description of language users subjective assumptions about meaning. Semantics must be something other that the production of psychological descriptions of human language skills. Experiences with misunderstandings and other mistakes show us that there are true and untrue implicit assumptions about the meaning of language. Hence, a test of the adequacy of a semantic theory will be whether it is able to account for these mistakes, i.e. explaining why the mistake arises and how, in principle, it could have been avoided. An adequate semantic theory will be able to generate solutions to all linguistic errors, account for the frequency of these errors, etc. An adequate semantics for talking about natural kinds will, therefore, be able to account for - if this should be the case - why talk about natural kinds sometimes gives rise to special communicative difficulties (especially where the people apply divergent ontological views on nature).

When I say that an adequate semantic theory must be able to account for all errors, this may seem to run counter to a central criterion for all scientific theories, namely that one must be able to imagine a situation in which the theory in principle be in conflict with an actual state of affairs. For the case of semantics this implies that one must be able to imagine a type of error that the theory would not be able to account for. When I say that we will be able to account all errors, I am referring to actual errors.

There is always a risk that theory will be unable to explain an error, and that we will, thus, have a counter-experience. As I see it, the criterion of testability is satisfied, as far as it is reasonable to expect this of a theory of meaning (semantics). The idea is that e.g. errors arise when certain semantic conditions are not satisfied. If these conditions are correctly given, misunderstandings will not occur in cases where the given conditions occur. At the point when the semantic theory gives these conditions, the theory will be exposed to a risk of being refuted through concrete examples of language use. We can think experimentally: Let us assume that we have a semantic theory that implies that when conditions B1 and B2 are not met, a certain type of misunderstanding, $\mathrm{M}$, will arise. We can, thus, establish a situation where B1 and B2 are not met, and see whether confusion arises.

I have assumed that meaning and reference are conditioned by the actual state of affairs. This implies, on the basis of my understanding 
meaning as being given by truth conditions, that truth conditions for a given sentence are given by statements that contain exclusively factual terms. This factual understanding of semantics is in clear opposition to newer antirealistic tendencies in philosophy of language. I, thus, propose a semantic realism, and it may appear to be so radical that central terms in the philosophy of language cannot be accounted for, terms such as understanding, language learning, and the use of language, in general. At the least, it can seem to entail an inability to regard language as a social product, and the changes and dynamics that characterise language.

As I see it, there is a duality in language: On the one hand, language changes continuously, and this change is conditioned by social interaction. This represents the dynamic aspect of language. On the other hand, language represents an institution independent of the individual speaker. We are born into language, and part of our human undertaking is to conquer the world of meaning. We have failures and successes in our uncountable attempts to discover meaning in language. The entire language-learning situation presumes that there is something to grasp beyond us, and in relation to which we must establish all our epistemic skills in order to grasp it. Yet, we have confidence in the language community into which we are born, despite experiencing from early on that this community to which we belong can make errors in its postulation of meaning. We learn that it is possible to make mistakes about meaning, and this presumes that meaning is independent of the individual language user. We can still assume that there are some competent people who know how language expresses meaning, and that it, therefore, is clearly conditioned by its users. But, sooner or later, we are also capable of questioning these assumptions, and we do so on the grounds of our feeling that something is true or untrue independent of any linguistic authority. Meaning is given by something independent of the human epistemic capacity. This is the semantic aspect of language. An important question that, then, arises is what to consider in order to grasp the meaning of language.

Thus, there are aspects of language that fall outside semantics. Traditionally, these have been termed 'syntax' and 'pragmatics', respectively. When language users communicate, the underlying assumption is that language expresses a certain meaning. Sometimes, this understanding can be unclear, sometimes precise. Our assumptions about linguistic meaning are, therefore, hypothetical and are confirmed through other language users. This way of grounding a hypothesis of meaning is trusting and, in a way, naïve, 
but in practical communication often the only way available. The hypothetical meaning that we, as language users, have in mind, is a psychological matter and arises on the basis of evidence we succeed in making available and/or relevant. It is, thus, conditioned by the language users epistemic possibilities, and must be accounted for on this basis. This task I assign to pragmatics.

Syntax is concerned with the structural aspect of language, whilst, I maintain a sharp distinction between semantics and pragmatics, I will see semantics and syntax as closely connected. As my inquiry will go on to show, I see the syntax of language as the mechanism that arranges and distributes components of meaning acquired through the relations of reference.

The duality I identified above, namely the independent status of language, on the one hand, and its historic and dynamic function on the other, can be accounted for in different ways. Dummett has for example tried to overcome the challenge by consistently taking the epistemic/pragmatic aspects as his point of departure. My strategy is to make a historic (chronological) distinction: Language starts with a pragmatic phase, where the relations of reference and structure are created. When this phase is completed, the semantic stage arises. At this point, the creation of meaning has occurred. The semantic stage involves its objects appearing as liberated and independent (autonomous) in relation to epistemic constructs. Semantic terms represent factual objective matters. An account of the duality of language is thus provided by a historical division between the creation and being of language; a semantic "deism".

This may sound far-fetched, but it is not. That the objects of semantics are something ontologically given arises from the fact that we can make misstakes about the meaning of sequences, and do so under all epistemically conditioned situations. It is not conceivable that our ascription of meaning is incorrect if there is nothing for them to be wrong about, without such an objectification, a relativism of meaning would be hard to avoid.

\section{Syntactic aspects}

Simple examples demonstrate that syntactic aspects play an important role in determining the truth conditions of a sentence. The sentences (4) and (5) seem to be the same as far as the referents of the constituent parts is concerned: 
(4) Linda is taller than Rebecca.

(5) Rebecca is taller than Linda.

All the same (4) is true under different conditions that (5). The structural difference between them can be made explicit through the use of logical notation: ${ }^{22}$

(6) $\mathrm{H}(\mathrm{a}, \mathrm{b})$

(7) $\mathrm{H}(\mathrm{b}, \mathrm{a})$

I find the use of symbolic logic to make explicit the syntactic aspects of language that are relevant for meaning very productive. But, the renderings (6) and (7) are empty of meaning, and in themselves not adequate to account for the meaning of (4) and (5). At this point, we need the aspect of reference to supply the statements with meaning. How I conceive this will become gradually apparent when I try to explain the relations of reference for the referential terms of sentences. Let me first hold the aspect of reference aside to focus exclusively on syntax.

In 'Syntactic Structures' (1957) Chomsky formulated a new way to think about grammar, and started what is called generative grammar. Chomsky claims that it is syntax that should be central to our attempts to describe a language, which implies that one formulates the rules and principles that govern the way a language is built up. Herein lies a great challenge, since language contains the possibility for an infinity of different sentences. The rules and principles that make up a description of language must, therefore, take this into account by forming the basis of an account for any well-formulated sentence in the language. If the description is adequate, the given set of rules and principles will be capable of generating all and only those formulations that are grammatically acceptable. Along with Chomsky's work, I have found inspiration in the work of Montague.

What constitutes an answer to the problem of meaning for talking about natural kinds will become clearer if we take the first simple steps towards a formal representation of L. It is solely the syntactical aspects of $\mathrm{L}$ that will be dealt with to start with. This means that I will disregard the fact that the words 'gold', 'tiger', 'tree', etc. or other types of expression in L carry meaning. These words could, therefore, just as well (or better) be replaced by symbols without content. It is this level we must be concerned with if we are to construct a formal representation of $\mathrm{L}$. We are concerned with a (formal)

22 The letter ' $\mathrm{H}$ ' symbolises the relation ' ... is taller than.....' 'a' represents Linda and 'b' Rebecca. 
representation of the semantically relevant structure of $\mathrm{L}$.

Such a representation involves distinguishing various categories of primitive expressions: Variables, constants of entities and predicatives (single and multiple predicatives). Furthermore, a formal representation of talking about natural kinds contains recursive rules which represent the rules that underlie actual communication about natural kinds. These rules tell us how the primitive expressions can be combined to make longer expressions (rules of formation), and how an expression can be restructured (rules of transformation). This will result in what I shall call a formal system. This implies that a formal system for $\mathrm{L}$ is, at the same time, a formal representation of $\mathrm{L}$.

Such a formal representation of $\mathrm{L}$ will not result in a satisfactory semantics for $\mathrm{L}$, even if it were to give us a representation of all the syntactical possibilities that lie in L. As I have already shown the syntactical aspect is only half the answer; in addition we need the aspect of reference.

These first steps towards a syntactical (formal) representation of $\mathrm{L}$, are in line with logic of the first order. There are two features that should be presented: Firstly, the number of variables, constants of entity and predicatives are, in principle, unlimited. We are free to introduce as many as we want, even though what we introduce will always be a limited number. Secondly, complex combinations of symbol sequences can be constructed on the basis of a finite set of rules. These two features show an important characteristic of generative grammar: An open class of possible constructs from a final point of departure. This is seen as a basic feature of L, and, of course, of natural language, in general. We can construct and understand an infinite number of different sentences, but our competence is based on a finite number of rules, constants of entity, predicatives, etc. I will not go into a detailed formal representation for $\mathrm{L}$ here. It can easily be done in line with that which we find in Carnap and Tarski or newer approaches. Instead, I will mention that this approach to the syntactical aspect of meaning is identical to what Chomsky's thesis about natural speech expresses, namely:

(CT) Any natural language can be described as a formal system.

I accept this thesis, which means I accept that L can be described as a formal system. I do not, however, want to follow Chomsky's method of constructing a generative grammar. (CT) does not imply this specific method. However, the idea of a generative grammar enables us to account for how we, as users of $\mathrm{L}$, are capable of producing well-formulated formulations that 
have not been produced before. Not only that: Knowledge (tacit knowledge) of the rules that govern language enables us to understand completely new formulations. This means we know how the meaning of the structureless expressions is to be distributed in relation to complete formulations. I have gone on to claim that meaning is supplied to sentences through the relations of reference. It is this last aspect - the referential component - and more precisely the problem of reference for natural kind terms that I will look at in what follows. Before I turn my attention to this problem, I will make an important distinction.

\section{The distincion between reference and denotation}

I will distinguish between reference and denotation. The reason for drawing this line is that it is not plausible to identify the meaning of structural terms with the entities or classes of entities that are talked about. In making this distinction, I can also show where meaning is supplied to the sentence, i.e. where we find reference.

'Reference' will only be used in connection with structureless terms, whilst 'denotation' is used of structural terms. Among natural kind terms, we find both structurless and structural terms. 'Gold' and 'water' are structurless terms, though 'hydrogen oxide' is not. These latter terms (structural terms) point to things in reality on the strength of the references to the expressions involved. The difference between 'water' and 'hydrogen oxide' tells us something about how knowledge about the world changes language.

My line of thought is that reference occurs only in connection with singular (and, therefore, structureless) terms. This means that reference to water starts with a simple grounding. Water is grounded in some instance of water, but is then combined with a rule that tells the language user that 'water' should be used also when we talk about other instances of water, that means other entities with the feature F. Hence, natural kind terms refer to new instances on the strength of a rule or a norm.

This implies amongst other things that I do not make any distinction between, for example, proper names and natural kind terms as far as their ability to supply statements with meaning is concerned. Their relations of reference are probably of different natures, but this difference does not play a role in how they supply meaning to a statement. 
An example from Quine can demonstrate my point about the distinction between reference and denotation ${ }^{54}$ :

(8) Creature with a heart

(9) Creature with a kidney

Quine used these general terms as an example of co-extensionality, since (8) and (9) seem to talk about the same class of entities. Given the thesis that meaning is given exclusively by reference and structure, (8) and (9) should be semantically synonymous. They are about the same entities and have the same structure, and should, thus, have the same meaning. Yet, (8) and (9) do not mean the same. The fact that (8) and (9) are co-existential, and, yet, different in meaning would seem to be incompatible with the semantics I propose, but it can be solved through the introduction of the distinction between reference and denotation.

If (8) and (9) are alike in structure, the difference in meaning must lie in their different reference. This is precisely my claim. And this gives us the distinction between reference and denotation. (8) and (9) have the same denotation, but not the same reference.

This is how my distinction between reference and denotation works: (8) contains two terms that refer, 'creature' and 'heart'; whilst (9) contains 'creature' and 'kidney'. Both (8) and (9) entail reference to creature, and are co-referential so far. The difference in reference between (8) and (9) consists, then, in (8) also referring to heart, whilst (9) also refers to kidney. The relations of reference that are to be found between (8) and reality on one hand, and (9) and reality on the other, are not the same (8) and (9) are, thus, not co-referential, and not semantically the same as regards meaning. And, yet, the components of meaning that make up (8) and (9), and also the structure they have, mean that they are co-denotative. As I see it, neither (8) nor (9) refer in their entirety, despite them both containing referential terms. 'Reference' is used only for structureless terms. And, as I have said, I shall go on to identify their meaning with their reference.

This has the consequence that the sentences

(10) Barbara is a creature with kidneys.

(11) Barbara is a creature with a heart.

Have different meanings, which again implies that they have different conditions of truth. That this is the case is shown in that they have different

54 I think, however, that Quine would not accept my analysis of (8) and (9). 
truth value if we assume that Barbara had an operation where her kidneys were removed, and that Barbara, then, had to take a (new and as yet undiscovered) medicine that could replace kidney function.

Let us use an example, which include the use of a natural kind term:

(12) Barbara drinks water.

(13) Barbara drinks hydrogen oxide.

The sentences do not express the same meaning and we have to explain why. The terms 'water' and 'hydrogen oxide' seem at first sight to have the same reference. However, according to my distinction between reference and denotation the term 'water' is a structurless term, while 'hydrogen oxide' is not. Hence, we should expect different meanings expressed by (12) and (13). Then, we have an explanation why (12) and (13) obviously express different meanings. The movement from the term 'water' to 'hydrogen oxide' reflects the increased level of scientific knowledge, and give an example of how science influences the meaning of $\mathrm{L}$.

However, a question that is likely to arise is how the distinction between reference and denotation functions for Frege's famous example of 'The Morning Star' and 'The Evening Star'. Since these terms have been regarded and treated as structureless and co-referential, we would expect that they also have the same meaning. The answer to this is that Frege's terms are not structureless, since they are both made up of smaller expression 'morning', 'star' and 'evening'. Other constructions are possible, namely 'The Star Morning' or 'The Star Evening'. Could one then envisage the same analysis as for (10) and (11)?

First of all, it seems to be very difficult to carry out such an analysis with Frege's example, since 'The Morning Star' and 'The Evening Star' do not function as general terms, but as names. Another argument is that we can easily think of names that apparently mean different things to different language users. The Danish philosopher wrote under the pseudonym 'Victor Eremite', and one associated a different content of meaning to this authorial name than to the name 'Siren Kierkegaard'. I can lay it out like this:

(a) Viktor Erimita

(b) Søren Kierkegaard

The names (a) and (b) thus seem to be different as regards meaning, but, at the same time, co-referential. I shall claim, however, that (a) and (b) are co-referential and, therefore, have the same meaning. This does not prevent language users and readers from associating different meanings to (a) 
and (b) at certain points in time, but this will always be hypotheses of meaning or subjective ascriptions. We are concerned here with different hypotheses of meaning, where at least one of them (for one and the same language user) is untrue. Or to put it another way: One and the same language user can have two different hypotheses about meaning, one for (a) and one for (b), and, if they are not the same, one of them is untrue.

This seems to raise a new problem, namely conclusions in intentional contexts:

(14) Martin thinks that Father Christmas is dangerous.

(15) Father Christmas = Daddy

(16) Martin thinks that Daddy is dangerous

It is quite possible here to hold the premises to be true, without accepting the conclusion. One should not expect this, if I am correct in maintaining that meaning is identical with reference. The reference for 'Father Christmas' is Daddy, as is stated in the second premise. This means that the meaning of 'Father Christmas' is identical with that for 'Daddy'. How, then, can Martin hold that Father Christmas is dangerous, and, yet, not hold that Daddy is dangerous?

There is a simple answer to this question: Martin does not know that 'Father Christmas' has the same meaning as 'Daddy'. ${ }^{55}$ Martin's hypothesis of meaning is untrue, and had he known this, he would have held the first premise to be untrue (and the conclusion too, of course). What is wrong with the above argument is that semantic meaning and the ascription of meaning (in this case Martin's) are confused. Premise (14) makes a claim about Martin's assumption of meaning, i.e. what 'Father Christmas' refers to, and that this reference is dangerous. This is what constitutes belief. Except for contexts of belief, we presuppose that the ascription of meaning is the semantic meaning. The argument above shows, as I see it, an example of how semantic meaning and the ascription of meaning can part company. (14) is based on a certain ascription of meaning, whilst (16) is based on semantic meaning.

If one is to correct this, one must argue consistently, at the same level, throughout a line of reasoning. This underlines the importance of the

\footnotetext{
55 'Meaning' must not here be understood as something we have in our heads, but as a semantic quantity that is to be found independent of our separate consciousnesses.
} 
distinction between meaning and the ascription of meaning. To correct this, one could reformulate (15), as follows:

(15) Martin thinks that Father Christmas = Daddy.

From this, (16) follows without difficulty. Under such circumstances, it is impossible to hold (14) and (15') for true, and (16) for untrue.

Now, there are examples of arguments that contain intentional terms, without these creating problems, even if certain statements are purely extensional:

(17) If the sun is yellow, then, Paul believes that the sun is yellow.

(18) The sun is yellow.

(19) Paul believes that the sun is yellow.

The statements (17) and (19) contain 'believes', whilst (18) does not. We have here a heterogeneous argument. The reason that this argument does not create problems for us is that it is found, at the same level, logically speaking. The logic of statements does not encompass the structure that the atomic statements have, and, thus, it does not matter whether they contain 'believe' or other intentional terms. Now, one could analyze the argument, at the level of predicative logic, and, indeed, we could enter the field of the logic of belief. But, such analyses would not add applicable components of structure to the argument. Its applicability is not affected by these syntactic components.

\section{The Problem of reference for natural kind terms}

One move for a referential semantics for $\mathrm{L}$ is to let reference play the role of a fundamental semantic term. In this way, the explanation of what reference is comes under strong pressure. Tarski's definition of 'truth' does not help us broach the term 'reference', since Tarski's term of satisfaction remains undefined. ${ }^{56}$ Tarski's definition is, however, important to my approach of semantic meaning. But, it cannot give a complete account, as Davidson and his adherents have claimed. A referential semantics for $\mathrm{L}$ needs a theory of reference.

The problem of reference for natural kind terms consists in accounting for how, for instance, 'hydrogen' is linked to hydrogen. Since I

${ }^{56}$ Paul Moser (1989) has argued that this is concerned with giving the preconditions that every definition of truth must make. 
understand 'hydrogen' as a structureless term, I am, basically, faced with the same phenomenon, as when I encounter the problem of how 'Socrates' is linked to Socrates. The problem of reference for a natural kind term is, thus, a problem of accounting for a relation.

The problem of reference for the word 'hydrogen' is, off course, just an instance of the general problem of reference for all natural kind terms. It is, though, more clear to use a concrete example (a token to be more precise). Since a satisfactory account of how 'hydrogen' refers to hydrogen implies indicating the necessary and sufficient conditions for his relation, I can formulate the problem of reference for 'hydrogen', as follows: What conditions does ' $\mathrm{B}$ ' symbolise in $(\mathrm{S})$ if $(\mathrm{S})$ is true?

(S) 'Hydrogen' refers to hydrogen if and only if $\mathrm{B}$.

This is a concise definition of the problem of reference for 'hydrogen', and, hence, for all natural kind terms. The task is to find a suitable formulation for ' $\mathrm{B}$ ' in (S).

The formulation $(S)$ presupposes the existence of hydrogen. This means that I do not see it as being the task of a theory of reference to answer the question of whether hydrogen or some other natural kind exists. The problem of reference for 'hydrogen' is not a question of whether 'hydrogen' has reference, but of how 'hydrogen' refers to hydrogen, if hydrogen exists. The problem is, as I have already said, to account for a relation.

This means that semantics I defend is pure, in the sense that it does not imply the existence of certain entities or groups of entities. These hypothetical assumptions are also limited to what is necessary to solve the task of semantics, namely to account for linguistic meaning. ${ }^{57}$ Semantics has a model-theoretical obligation, which implies an ontology, beyond which one need not go. For a semantics for $\mathrm{L}$, it is necessary to assume that natural kinds exist. Then my way of thinking is a kind of essentialism. I will come back to this point later.

It is, however, clear that my talking about this reality of essences is at the model level and cannot be otherwise. The theory of reference that I will maintain in what follows will, therefore, rest in a postulate that the model, on which I base my discussion, is adequate to account for the relation of reference for the word 'hydrogen' and other natural kind terms. But, a model

57 The use of 'hypothesis' can lead to associations that I commit myself to 'hydrogen' being testable on a par with for example a hypothesis of reason in natural science. This is exactly my point of view. I believe natural kinds exist and science can discover them. 
is beset by the same problems that apply to any theoretical construction: the question of whether the model is true, of its simplicity, adequacy, explanatory strength, etc.

\section{The Reference Based on Meaning}

One way of solving the problem of reference for the word 'hydrogen' is to replace ' $\mathrm{B}$ ' by the statement:

'Hydrogen' expresses a meaning, and this meaning can be expressed by a description uniquely true of hydrogen. ${ }^{59}$

The line of thought is to understand reference as a process of identification: The language user associates a certain content of meaning to 'hydrogen', and, on the strength of this content, the language user can describe hydrogen uniquely and, thus, 'point hydrogen out' wherever it occurs. This view is to be found - in various versions - in Frege, Russell, C. I. Lewis, Carnap, and Searle.

With a slightly rounder formulation and with my concept of structureless terms in mind (which imply that natural kind terms supply meaning to sentences in the same way as singular terms), we can express the kernel in these theories with Wettstein's words:...the idea that singular terms express a descriptive concept and refer to those items that satisfy the concept" (Wettstein 1984:63). This way of thinking seems to presuppose a meaning that singular terms and natural kind terms carry before the term is, actually, used. Its primacy in this sense seems to be given by the fact that the language user succeeds or fails in his/her attempt at reference. To succeed or fail assumes a preceding point in relation to which the language use in question can be judged.

So far, so good. Problems arise, however, when we confront this meaning that has been already determined with the distinction between analytical and synthetic statements. It seems to follow that statements which talk about a referent with an identifying description fall into the class of analytical statements. If 'water' refers on the strength of meaning expressed

${ }^{59}$ (B1) is of course formulated without taking my distinction between meaning and the ascription of meaning into consideration. 
by 'water', for example, 'the transparent liquid for drinking and washing', then, the following sentence becomes a positive analytical statement:

(20) Water is the transparent liquid for drinking and washing.

To deny (20) will, thus, imply denying a sentence that is true in all possible worlds. How can we think of 'water' as referring to anything other than the transparent liquid for drinking and washing? (20) will be logically necessary, whilst the following sentence will be logically impossible:

(21) Water is not the transparent liquid for drinking and washing.

But, both (20) and (21) seem to be contingent. Neither of them seems to have the tautological character of, for example, 'all bachelors are unmarried'. Linking reference to meaning in this way seems, therefore, to lead us on the wrong track, since we no longer can conceive that a structureless term, such as some natural kind terms, refers to anything other than exactly what it pointed out by the description that expresses the meaning of the term..$^{60}$

There is, however, another criticism that can be made against the strategy of defining reference on the strength of meaning. A central precondition for the semantic programme I wish is that reference is a more fundamental term than meaning and meaning is what semantics seeks to account for. If this supposition is correct, (B1) will be very problematic. (B1) seems to imply an account of meaning on the strength of meaning To account for meaning on the strength of reference, and, then, to account for reference on the strength of meaning, is undesirably circular. Against this background, it seems clear that the traditional theory of description of reference, as it is formulated in (B1), is not the way forward.

If I relate (B1) to the semantic move I have chosen, the whole line of thought will become unreasonable. Linking reference to a process of identification is to mix the epistemic and the semantic aspect. Meaning is given independent of our epistemic possibilities, something identification of course is not.

In defence of (B1), it could perhaps be claimed that (B1) is not formulated in a satisfactory way. Another suggestion, which also belongs in the tradition of a theory of description, is to claim:

(B2) 'Hydrogen' is associated with a description, which is uniquely true of hydrogen.

\footnotetext{
${ }^{60}$ My impression is that this is a serious criticism, even though, it is possible - on Quine's premises - to reject the modal distinctions that the argument presupposes. I do not intend to discuss Quine's modal logic here, but refer to Dagfinn Føllesdal's doctorate. Possible worlds are, however, part of the given model I wish for $\mathrm{L}$.
} 
Here, I have avoided 'meaning' by using 'associated with'.61 The question is whether this solves the problem of circularity. At first glance, (B2) seems to have avoided the problem, although, 'is associated with' is to me unclear. In what does the association consist? What determines that we receive the appropriate association, i.e. that we associate descriptions that are true about hydrogen and about hydrogen alone? Can 'is associated with' function as an account of the relation of reference for 'hydrogen' or another expression? This doesn't look at all like an explanation to me - it looks more like a smoke screen.

It seems to be the case that a language user can succeed in referring to entities, even if he/she does not have associations to an appropriate description. Kripke's well-known example is that very many language users associate 'Columbus' with the description 'the discoverer of America'. This description is not true of Columbus, but, yet, the language user succeeds in referring to Columbus, by 'Columbus'. The same can be said of children's use of 'gold' or 'water'. I can, therefore, draw the conclusion that a true association of a unique identifying description is not a necessary condition for reference (whilst, I would not by this deny that such a description constitutes a sufficient condition for reference).

This does not mean that the content we link to a structureless term is without significance for the language user. In order for an autonomous use of a structureless term to take place, a relatively adequate content must have been linked to it. If a language user on his/her own is to be able to identify the referent of a structureless term, that person must be in possession of information that makes this possible. The same applies to the use of 'water', 'hydrogen', etc. But - as I have already emphasised - I shall make a radical division between reference and identification. A language user can de facto be capable of referring, even if this person lacks the ability to identify. Kripke's example about 'Columbus' demonstrates this to be the case. This also means that I reject an anti-realistic approach, i.e. an approach that makes reference and meaning dependent on the language users epistemic possibilities. I understand identification as an epistemic term, and reference as a semantic term. In my view, mixing these two aspects misunderstands the concerns of semantics.

61 This way of formulating the theory of meaning about reference is in line with that which Kripke argues against in "Naming and Necessity". 
By this, I do not deny that there is a relation between the epistemic term of identification and the semantic term of reference. My point is that they are two different concerns: If a language user, $\mathrm{P}$, has the ability to identify hydrogen or water through the use of language, $\mathrm{P}$ is also capable of referring to natural kinds like these through language (since a semantic relation of reference already exists), but not vice versa. It is a consequence of our ability to use language that we also have the ability to refer. This conditionality presupposes that identification does not only consist in producing a true description of an entity or a set of entities. It is quite possible for $\mathrm{P}$ to produce a description, which happens to be true of something or other, without $\mathrm{P}$ being capable of identifying what the description is true about. 'identification' is a term that implies a result. It is this condition that the conditionality above is to be held as true. We can, therefore, say that the mistake of the anti-realist is to link semantic possibilities to the language users epistemic possibilities. Actual use of language shows us that a language user can succeed without, in fact, being aware of doing so, indeed without the possibility of investigating the matter. $^{62}$

\section{Reference based on Causality}

The question that arises is whether there is a way that avoids meaning. Can reference be accounted for without employing the term meaning? John Stuart Mill claimed a position on names that was quite different from the one that finds expression in (B1) and (B2). A name, e.g. 'Dartmouth', refers to the town Dartmouth on the strength of something other than the meaning expressed by the name. This is clearly apparent in that the river Dart changed its course, so that the town Dartmouth no longer lies at the mouth of the river. Mill does not make clear what it is that ensures the relation of reference between 'Dartmouth' and the town, but it seems to have to do with a process of transfer running up to our current use of the name.

\footnotetext{
62 At times, a language user can be in a situation where he/she is able to identify an entity or a natural kind, but unable to give a unique true description of the entity or the natural kind. This is the state of affairs when a witness can pick out by sight a suspect amongst several people who resemble the suspect or a language user can pick out every member of a natural kind.
} 
In my view, Mill points out a feasible method of approach, also for natural kind terms. Donellan, Kripke, Evans and Putnam developed Mill's line of thought further, amongst others, in the 1960's. Especially, Kripke's discussion has been significant. A so-called causal theory of reference was developed: An expression refers to its referent on the strength of a certain chain of causality that stretches from the referent and on to the current use of the expression. This can be expressed in the following way for 'hydrogen':

(B3) There is a chain of causality that stretches from hydrogen to 'hydrogen'.

The benefit is that the language user's ability to identify the referent, i.e. to possess identifying knowledge, becomes irrelevant in relation to that person's ability to refer. In this way, the ability to refer can be accounted for in a way that is consistent with the examples mentioned above. 'Einstein' and 'hydrogen' refer even if the language user is unable to produce an identifying description, or even if he/she, in good faith, produces a description that identifies the wrong person or wrong natural kind, or nothing at all. These views fit the semantic program I have developed so far. I shall, however, distance myself from (B3).

If causality alone functions as a primitive term in a semantic theory, the consequence will be that a number of cases of reference will remain unexplained. It seems reasonable to think that causality occurs exclusively between physical entities. There are, however, cases of reference that is semantically different, but at the same time physically equivalent. Imagine I utter the following sentence:

(22) Arne Næss was a good mountaineer.

I refer to Arne Næss on the strength of my use of language. ${ }^{63}$ So far, so good. The problem arises when the receiver discovers that 'Arne Næss' is multi-referential (semantically speaking): By this sentence, I can refer to the financier Arne Næss or to the philosopher Arne Næss, and (22) contains no information that can discriminate between these two possibilities (since both were good mountaineers). The question is now whether the term of causality alone is sufficient to account for which referent I am actually referring to in utterance (22). It seems clear that there is no physical difference between the two possibilities for reference - and, therefore, (B3) must be rejected. The

63 'Use of language' here entails only that it is the language user who produces the statement. The meaning of the statement, however, is independent of the language user. 
sequence of sound that I produce in uttering (22) can be completely identical, either I refer to the philosopher Arne Næss or the financier Arne Næss. If we were able to point out a discriminating difference, we seem to be forced to go to the consciousness of the language user. It is the language user's choice of reference that is decisive; only then can we talk of a freedom of choice that makes these phenomena of reference possible. Then it follows that causality cannot explain all cases of reference. Direct Reference

I have claimed earlier that the meaning of sentences is given by the reference of structureless terms, and by the structure of statements. The relations of reference that underlie the structureless terms supply meaning to the statement, and the structure of the statement orders this meaning. The thesis that the meaning of a statement is given by its conditions of truth is built upon these relations. It has been important for my analyses to maintain that the conditions of truth, and, therefore, of meaning, are given independent of the language users' epistemic abilities or their ascription of meaning. I want to maintain a direct theory of reference. Meanings are actual or factual matters. The 'meaning' the language user has in her/his head I will call 'ascriptions of meaning', and claimed that these need not coincide with the meaning of the sentence (i.e. its semantic meaning). Meaning is something that occurs independent of the contents of the language user's consciousness - albeit not independent of the language user's consciousness, as such. 64

This view raises a series of issues about the language user's role. Is it really possible to draw such a distinction? Is not language linked to usage? From one point of view, it seems impossible to imagine a situation where language occurs, spoken or written (ancient texts for that matter), without it occurring as language in use. How can the radical distinction I have developed and presupposed be plausible?

From my distinction between ascriptions of meaning and semantic meaning, it does not follow that the consciousness of the language user is without semantic relevance. Nor does it follow that the consciousness of the language user cannot play a key role in my semantic theory. What does follow, however, is that the content of the language user's consciousness, in the sense of ascriptions of meaning, understanding, etc. cannot play a role. If I allow the contents of consciousness to play a decisive role, I return to the

${ }^{64}$ What I intend by this addition will become clearer below. 
theory of meaning about reference, and the problems such a theory entails. Drawing this consequence indicates that the language user's consciousness will play an important role in my semantics. But, the content of meaning, the representations, feelings, or whatever consciousness should contain, is irrelevant for the semantic theory I am working towards.

\section{Grounding}

In order to state a direct theory of reference, I will follow Michael Devitt (1982), and divide the relation of reference into two main components:

(a) The grounding

(b) The establishment of a name.

Though, the establishment of a name will chronological happen after a grounding event, it can be easily be explained previously to my account for groundings. When a grounding relationship is created to an entity the language-user can link a name to this relationship. Then, this name can be used effectively, according to the grounding event. This is a social process and the introduction of the name will be successful only if the language community accepts the introduction.

I will now give attention to the event of grounding. Imagine I came into a pet shop last Saturday to buy a parrot. Inside the pet shop, I orient myself with regard to the parrots through my senses. I register the parrot, and I am attentive of the parrot. Registering something is in a certain sense involuntary, but all the same it presupposes a certain state of consciousness. Most people have experienced 'seeing without seeing'. I can be mentally absent in such a way that I fail to register visual impressions. Or, I can be so concerned to look for a particular entity that all other entities fade into the background and do not gain my attention. If I look towards a cluster of trees to see a friend, I will not register the pine tree closest to the path, although this tree is in my field of vision. The tree is not much different from all the other trees, nor am I looking out for pine trees. Had this tree had a red trunk and yellow needles, I would quite certainly have registered the tree, even though, I was looking out for my friend. The extent to which a registration takes place is, thus, (at least) dependent on certain circumstances beyond the fact of my senses being directed towards the entity. Aspects of the entity and/or my consciousness play a part and set the conditions. Almost the same description 
can be made if I was looking at trees in general. My focus would have been different, but would have been at individual trees - not one but several individual trees.

Apart from this, conditions of a more fundamental nature seem to be present. A registration seems always to be partial in relation to the whole field of vision. Hence, it is independent whether we introduce a singular term for the actual entity or a general term/natural kind term. Consciousness focuses on certain things within a larger field of vision. This presupposes an ontological assumption about entities. We individualise reality: A tree, a car, a person, etc. Our model of reality is made up of such entities, and this finds expression in language. Whether reality can be modelled in this way, or whether it is epistemically defensible is indifferent for the description I am now giving. My point is that we actually seem to do it in this way, and that the relations of reference are created against this naive (and confident) background. On this background, I will use 'nominal essence' in lockian sense. Users of language seem to classify certain objects as members of the same natural kind because they perceive those objects carry certain common properties. But, this classification is done upon this naive (and confident) background. Putnam talks about 'stereotypes', but that presuppose that we already have made a classification. Grounding will not always happen on basis of a ready classification. In my view, grounding for a natural term will happen in strength of similar properties among two or more entities. Hence, the grounding upon an entity will just be partly, i.e. linked to some certain properties of the entity. This reduced grounding point is all that is necessary for the language user's purpose. When we talk about trees, we don't need to identify a specific tree. When we talk about a specific parrot, we need grounding in some more properties, in order to identify that specific parrot. These differences in need give raise to two different groundings, and, then, give raise to two different kinds of meanings - singular and general concepts. These groundings are all created on basis of a naïve ontology. Later on, this primitive ontology could be developed and, hence, link the grounding in some more specific underlying, though, perhaps, currently unknown, common property - for example, in some micro structural property or in some genetic structure. This will, then, be the 'real essence' of that kind.

The grounding consists, then, in a relation between one (or more) language user's model (naïve ontology), $\mathrm{M}$, and an existing entity, $\mathrm{E}$, and entails the language user incorporating $\mathrm{E}$ as an existing entity in $\mathrm{M}$. The 
language user will also link certain properties to $\mathrm{E}$, and will be able to describe it in such and such a way. These descriptions can be completely wrong, so that they ascribe properties to $\mathrm{E}$ that actually do not belong to $\mathrm{E}$. All the same, this can be linked to E, if E exists at all. Though, there will not be an occurrence of reference if it happens that $\mathrm{E}$ does not exist.

As I have sketched grounding up to now, a referring term refers on the basis of the model. This does not imply that the adequacy of the model is a condition for reference. A model can be incorrect as regards its descriptions of existing entities. But, if the model assumes the existence of an entity, which an expression in the language claims to refer to, this expression will be meaningless if the model is mistaken as to its assumption of existence. I, then, maintain that the distinction, between meaningfulness and meaninglessness, lies in ontology.

If we now analyze the aspects of grounding on the background of the concept of a model, the situation could be understood like this: I register the parrot or some trees and incorporate these in my model of reality. The model is a mental construction, and, at its highest level, it is a philosophical construction, where science makes a significant contribution. ${ }^{68}$

I can then give a further comment on the establishment of a name: When a grounding relationship is created to an entity - to some naive identifying properties or to some general common properties - the user of language can link a name to these properties, and use the name in different kinds of speech acts.

\section{Our Use of Natural Kind terms}

In my approach of the problem of meaning, I want to distance myself from the view that the relation of reference consists in a relation between language and the model, since a model is just a representation of (a part of) reality. The relation of reference, however, "shoots right through" the model and into reality as such. This way of talking distances me from understanding the relation of reference as an internal relation in the model. Then, the problem of reference involves the question of what kind of grounding we can have for a natural kind term. My strategy has been to look at the relation of reference for natural kind terms in the same way as for

$68 \mathrm{I}$, hereby, reject a scientism where science, e.g. natural science, is understood as the only valid producer of knowledge for an understanding of reality. 
singular terms, or more specific for proper names. I am searching for a onetype-theory of reference for every structureless term in L. The problem I face here is the problem of approaching the difference between the following two sentences. When we say

(23) Lions eat other animals.

we succeed in saying something about all lions. The sentence (23) has, then, different truth conditions than (24):

(24) Simba eat other animals.

If the meaning of a sentence is given by its truth condition, and its truth conditions is determined by its formal structure and reference of its structurless terms, we should expect (23) and (24) having the same conditions of truth - but they clearly don't.

As I see it, the difference of truth conditions between (23) and (24) has its explanation in the normative aspect of reference. This normative aspect allows us to use the term on several entities, not only on one specific entity. The use of natural kind terms has a general use, and singular terms have a singular use, but the first reference is in both cases grounded in a singular entity - though, natural kind terms give opening to repeat this relation of reference for several singular entities, as long as they belong to the same natural kind. Though, the relation of reference is singular in the same way as for proper name or singular terms in general, there is a difference in the way the term continue to refer. Natural kind terms allow us to apply the relation of reference to all members of a specific natural kind (or of what we believe is a natural kind). This does not imply that the relation of reference contains information that makes us capable of picking out any member of a natural kind. Our mental content of reference only expresses the intention, and could, on the other hand, be totally false about the term's factual reference. What makes us succeed is, however, the direct relation of reference. And, it makes us able to be wrong in our identification of the members of a natural kind. When a natural kind term allows us to use the term on members of a natural kind we never have seen before, there is always a risk of doing it wrongly.

Under which condition are we doing it right? We have seen that a natural kind can develop over time, and I have to take this fact into account for an answer of this question. As I already have mentioned, it seems to be a fact that an initial user of a natural kind term classifies certain entities as members of the same natural kind because they perceive those entities to 
have certain properties in common. In my view, these properties are the point of grounding for a relation of reference for natural kind terms. The relation of reference for singular terms and natural kind terms is, then, similar all the way, except for the grounding point on the actual entity. The normative aspect of the further use of the term, can be expressed as an obligation of using the term on every entity that has the property (or set of properties) that constitute the point of grounding for the given natural kind term. As I have mentioned already, the relation of reference for singular terms has broader grounding points than for natural kind terms. This gives raise to a different use of terms about natural kinds, than that of singular terms (for instance, proper names). Our successful use of a natural kind term is, however, not dependent of the speaker's ability to give the necessary and sufficient condition for a specific entity's membership of an actual natural kind. The first grounding of a natural kind term is based on a "common sense" application above a specific entity. Our closer acquaintance with the entity could result in a revision of the grounding point - as we have seen for 'water' $(\mathrm{H} 2 \mathrm{O})$.

On the basis of what has been said, I can attempt to give the conditions for grounding. I can, for instance, say that, at a certain point in time, a grounding occurs if and only if the following apply at that point in time: An entity, E, exists; a person is aware of E; and that, at the same time a representation of $\mathrm{E}$ arises in the model $\mathrm{M}$. My opinion is, however, that there is a strong connection between the representation in $\mathrm{M}$ and the entity, E. As this is formulated, my idea has not been kept, namely that the mental representation arises, as 'a result' of the entity. Without this strong connection, there will be no relation of reference, which can function independent of meaning or some identifying description of E. In my opinion, there must exist a kind of conditioned necessity between $\mathrm{E}$ and the representation of $\mathrm{E}$ in $\mathrm{M}$, and this is not expressed. I have said ' at the same time': but, this is not enough, since there need not be a connection between two factors, despite their occurring at the same time. To keep the last point, I shall reformulate this in the following way: At a certain point in time, a grounding occurs if and only if the following applies at that point in time: an entity $\mathrm{E}$ exists, a person experiences the entity, and that, as a result of this experience, a representation of $\mathrm{E}$ arises in $\mathrm{M}$, with conditioned necessity. This can be written out as three singular conditions for grounding: 
(a) The entity, E, exists.

(b) The person is aware of $E$ through an experience.

(c) A representation of $\mathrm{E}$ arises with conditioned necessity in $\mathrm{M}$ (as a result of the experience).

Conditions (a) - (b) give roughly the conditions that must be fulfilled if grounding can be said to occur.

This result is much the same as Devitt's (1981). An important difference is that Devitt does not make explicit the intentional nature of the grounding, and also that he bases the grounding on a physicalist term, as regards sensing. In my view, sensing alone does not entail that grounding takes place. I can see without 'seeing' if I am mentally absent. I see with my eyes, but I am not conscious of what I see. For the sensing to be adequate, my attention must be directed towards what I see. It seems, therefore, more accurate to say that we become aware of an entity through our senses, rather than just to say that we see. Devitt does, indeed, claim that "all groundings involve grounding thought” (Devitt 1981:133), which I see as presupposing that consciousness was directed towards the entity in an act of perception. But, Devitt does not say this explicitly. Yet, it is important to make this explicit, since it shows that the relation of reference already, at the point of departure, is intentional in character. Thus, we also discover that Devitt's analysis of grounding, as a primitive causal relation, is a simplification of what, actually, happens.

Devitt also uses the expression 'perception' which, in my definition, involves the 'structuring acts' of consciousness. But, Devitt seems to understand the act of perception as purely causal, that is, he uses 'perception', as I use 'sensing'. To keep these points separate, I would prefer 'experience', rather than 'sense'. Experience is spontaneous, even if it varies from model to model.

\section{Conclusion}

I have tried to answer the question of meaning and reference of natural kind terms in strength of a general semantic program in three stages: The first stage consists in an account of meaning for every use of a sentence in $\mathrm{L}$, by referring to its conditions of truth. The next stage consists in an account of how conditions of truth sentences in $\mathrm{L}$ are conditional to the structural role and the referential characteristics of the component elements. 
Finally, the last stage: An account of the referential characteristics of the component elements in L. Since I regard proper names as paradigmatic examples of how referential (non-structural) terms supply meaning to sentences, I took proper names as my starting point for developing a theory of reference for natural kind terms. This means I regard natural kinds as the meanings of natural kind terms, and the meaning of a sentence in $\mathrm{L}$ is given meaning through a syntactical distribution of the meanings of natural kind terms and other referential (structureless) terms.

The relation of reference between natural kind terms and natural kind has been explained in line of a theory of direct reference. Then, the relationship of reference is regarded independent of the content of the psychological ascription of meaning attached or associated to the term. In my opinion, the grounding of the relation of reference for natural kind terms is fixed to properties of the entity that the entity has in common with other entities of the same kind. Whether this property, in fact, is the essence of the entity or not, is, in principle, an open question. I believe there are natural kinds, but whether we have to do with a natural kind term or not, is dependent on whether the grounding point is fixed to the entity's essence or not. If it is, then, the term is a natural kind term. If not, the term is a general term of some other type. We cannot know for sure whether a given term is a natural kind term and expresses that kind of meaning. We can, however, have good reasons for believing it. I think we have evidence for believing that 'water' is a natural kind term, because science has discovered it's molecular structure. 


\section{Referências bibliográficas}

ASHEIM, O. Reference and intentionality. Universitetet i Oslo: Oslo, 1991.

ATKINSON, R. Introduction to psychology. New York: Harcourt Brace Jovanovich Inc., 1990.

AUSTIN, J. How to do things with words. Oxford: Oxford University Press, 1962.

BROWN, H. Perception, theory and commitment. The New Philosophy of Science. Chicago: The University of Chicago Press, 1977.

CANN, R. Formal semantics. An introduction. Cambridge: Cambridge University Press, 1993.

CHIERCHIA, G. \& MCCONNELL-GINET, S. Meaning and grammar. An introduction to semantics. London: The MIT Press, 1990.

DAVIDSON, D. Theories of meaning and learnable language. Finnes i Proceedings of the 1964 Congress for Logic, Methodology, and Philosophy of Science. Amsterdam: 1964.

. Truth and meaning. Finnes i Synthese 17, 1967.

. On saying that. Finnes i Synthese 19, 1968 eller i Davidson \& Hintikka. Words and objections. Hingham, Mass. USA, 1968.

. Semantics for natural language. Finnes i Visentini, B. (red), Linguaggi nella società e nella tecnica. Milano: Edizioni di Communità, samt i Davidson \& Harman, 1975. The Logic of Grammar. Encino: Dickenson Publishing Co. eller i Harman 1974. On Noam Chomsky. New York: Doubleday, 1970.

DEVITT, M. Designation. Columbia: Columbia University Press, 1982.

. Realism \& truth. Oxford: Basil Blackwell, Inc., 1991.

DRETSKE, F. Knowledge and the flow of information. Oxford: Basil Blackwell, 1981. 
DUMMETT, M. The philosophical basis of intuitionistic logic. Finnes i H. E. Rose \& J. C. Shepherdson (red). 1975. Logic Colloquium 1973. Amsterdam: 1975.

. Realism. Finnes i Dummett, M. 1978. Truth and other enigmas, s 145-65. London: Duckworth, 1963.

ELLIS, H. \& HUNT, R. Fundamentals of human memory and cognition. USA: Wm. C. Brown Publishers, 1989.

EVANS, D. The logic of self-involvement. London: SCM Press LTD., 1963.

EVANS, G. The varieties of reference. Oxford: Oxford Univerity Press, 1982.

FINE, A. "How to compare theories: Reference and Change". Nous, 9, 17-32, 1975.

K. "Essence and modality: the second philosophical perspectives lecture". Philosophical Perspectives 8: 1-16. 1994.

FREGE, G. 'Über Sinn und Bedeutung' Zeitschrift für Philosophie und Philosophische Kritik. Vol. 100, 1892.

FREUD, S. 1919. Civilization and its discontents, oversettelse av W. D. Robson-Scott. London: Hogarth Press, 1930

HACKING, I. "Natural kinds”. In: R. B. Barrett and R. Gibson, (eds.), Perspectives on Quine, Oxford: Blackwell: 129-141. 1990.

HALE, B. Realism and its oppositions. Finnes i A Companion to the philosophy of language. Oxford: Basil Blackwell Ltd., 1997.

HANSEN, C. Semantic realism and the anti-realist challenge. Balliol College Trinity term. Upublisert doktoravhandling, 1991.

HINTIKKA, J. Quantifiers in deontic logic. Soc. Sci. Fennica, Commentationes Hum. Litt.23(4), 1957.

HOLLIS, M. \& LUKES, S. Rationality and relativism. Oxford: Basil Blackwell. Oxford, 1982. 
JEFFREY, R. Formal logic, Its scope and limits. New York: McGraw-Hill Book Company, 1981.

JOHNSON-LAIRD, P. Mental models. Towards a cognitive science of language, inference, and consciousness. Cambridge: Cambridge Univversity Press, 1983.

KAMP, H. \& Reyle, U. From discourse to logic. Introduction to modeltheoretic semantics of natural language, formal logic and discourse representation theory. Dordrecht: Kluwer Academic Publishers, 1993.

KANGER, S. Provability in logic. Stockholm Studies in Philosophy, vol 1. Stockholm: Almqvist og Wiksell, 1957.

KOSLICKI, K. Natural kinds and natural kind terms. In: Philosophy Compass, 2008.

KRIPKE, S. Naming and necessity. Harvard: Harvard University Press, 1972.

S. Identity and Necessity”. In: Identity and individuation, M.K. Munitz, (ed.), New York: New York University Press, 135-64. 1971.

KUHN, T. The structure of scientific revolution. Chicago: University of Chicago Press, 1970.

LAKOFF, G. "Linguistic and natural logic", finnes i Semantics for Natural Language, sidene 545 - 665. red. av Davidson, D \& Harman, G. Dordrecht: D. Reidel, 1972.

LAPORTE, J. "Chemical kind term reference and the discovery of essence", Noûs, 30: 112-132. 1996.

Natural kinds and conceptual change. Cambridge: Cambrigde University Press. 2004.

LINSKY, L. "Reference and Modality". Oxford readings in philosophy. Oxford: Oxford University Press, 1971.

MARTIN, R. M. The meaning of language. England: The MIT Press, 1994.

MCCAWLEY, J. "Syntactic and logical arguments for semantic structures". In Three dimensions in linguistic theory, side 259 - 376. (ed.) Fujimura, O. Tokyo: The TEC Corporation, 1973. 
MCCULLOCH, G. The game of the name. Oxford: Oxford University Press, 1989.

MILL, J. A system of logic. London: John W. Parker, 1851.

MOSER, P. Knowledge and evidence. Cambridge: Cambridge University Press, 1989.

MUMFORD, S.'Kinds, Essences, Powers', In Ratio 18: 420-436. 2005.

PIAGET, J. Språk och tanke hos barnet. Lund: 1973.

PUTNAM, H. Reason, truth and history. Cambridge: Cambridge University Press, 1981.

QUINE, W. From a logical point of view. Harvard Harvard University Press, 1953. . Word and object. USA: The MIT Press, 1960.

RAMBERG, B. Donald Davidson's philosophy of language, An introduction. Oxford: Basil Blackwell Ltd., 1989.

RUSSELL, B. On denoting. Finnes i Marsh (red). 1956. Logic and knowledge. London: Allen \& Unwin, 1905.

TARSKI, A. The semantic concept of truth. Finnes i Linsky, L. 1952. Semantics and the Philosophy of Language. USA: The University of Illinois Press at Urbana, 1944.

THOMASON, R. Formal philosophy. Selected papers of Richard Montague. Yale: Yale University, 1974.

VAAGS, R. Egennavnenes referanserelasion. Universitetet i Oslo: Filosofisk institutt, 1992.

WRIGHT, C. Realism, meaning and truth. Oxford: Blackwell, 1987.

E-mail: Ralph.h.vaags@uia.no

Recebido: junho/2009

Aprovado: julho/2009 